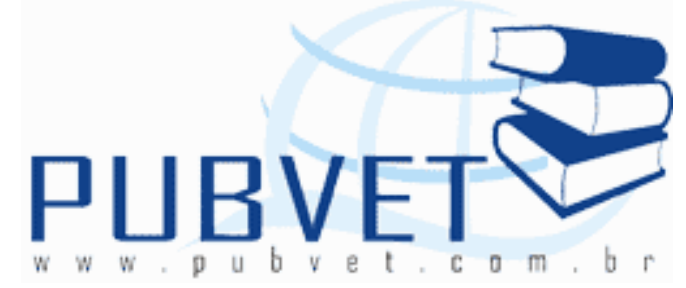

PUBVET, Publicações em Medicina Veterinária e Zootecnia.

\title{
Utilização da homeopatia para redução da contagem de células somaticas (CCS) em vacas Girolando
}

\begin{tabular}{l}
\hline Leonardo de Paula Leal ${ }^{1}$ e Cláudio Costa ${ }^{2}$ \\
${ }^{1}$ Medico Veterinário - Autônomo. \\
${ }^{2}$ Professor Titular da FUCAMP - Monte Carmelo - MG.
\end{tabular}

\section{Resumo}

A mastite é um dos problemas recorrentes na bovinocultura leiteira, sendo sua terapêutica onerosa e fonte de problemas de saúde pública, além dos seus prejuízos deixados ao produtor. Este trabalho objetivou-se avaliar a utilização terapêutica de homeopatia como alternativa para redução da contagem de células somáticas (CCS) em vacas Girolando. Quarenta e oito vacas em lactação foram divididas em dois lotes. Um com vacas abaixo de 120 dias de lactação (24 vacas) e outro com vacas acima de 120 dias de lactação (24 vacas), onde cada lote foram sub-divididos aleatoriamente em dois grupos de 12 vacas, sendo um grupo controle ( $\mathrm{T} 1$ ) e um tratamento (T2) abaixo de 120 dias; e acima de 120 dias um grupo controle (T3) e tratamento (T4). Experimento realizou-se por 100 dias (de 14 de fevereiro á 24 de maio de 2012). Os grupos de tratamento receberam 10 gramas de homeopático nos 15 primeiros dias e 5 gramas nos demais 85 dias. Foram feita quatro analises de leite, individuais por vaca, avaliando a CCS; sendo feita um no inicio do tratamento e mais três em um intervalo de 30 dias, estas analises foram feitas na clínica do leite ESALQ - USP. Além da CCS, foram avaliados os índices de 
LEAL, L.P. e COSTA, C. Utilização da homeopatia para redução da contagem de células somaticas (CCS) em vacas Girolando. PUBVET, Londrina, V. 7, N. 14, Ed. 237, Art. 1562, Julho, 2013.

mastite clínica no período. Os resultados foram calculados em dado estatístico, onde não ouve diferença nos grupos que receberam homeopático em relação aos grupos que receberam, independente se estava abaixo ou acima de 120 dias de lactação $(P>0.05)$. Conclui-se que a suplementação em vacas leiteira com produto homeopático não apresentou eficácia na redução da CCS.

Palavras-chave: mastite, bovino leiteiro, homeopatia.

\section{Use of Homeopathy for reduction somatic cell count (SCC) cows Girolando}

\section{Abstract:}

Mastitis is one of the recurring problems in dairy cattle, and its costly therapy and source of public health problems, and their losses left the producer. This study aimed to evaluate the therapeutic use of homeopathy as an alternative to reducing somatic cell count (SCC) on cows Girolando. Forty-eight lactating cows were divided into two lots. A cow with under 120 days of lactation (24 cows) and one with cows over 120 days of lactation (24 cows), where each sub-plot were randomly divided into two groups of 12 cows, and a control group (T1) and treatment (T2) below 120 days and over 120 days a control group (T3) and treatment (T4). Experiment was carried out for 100 days (February 14 will May 24, 2012). The treatment groups received 10 grams of homeopathic the first 15 days and 5 grams in the other 85 days. Four analyzes were made of milk per cow individual, assessing the SCC; being made one at the beginning of treatment and three in an interval of 30 days, these clinical analyzes were made on the milk ESALQ - USP. Besides the SCC were assessed indices of clinical mastitis in the period. The results were calculated statistic, which does not hear a difference in the groups receiving homeopathic compared to groups that received, regardless whether it was below or above 120 days of lactation ( $P>0.05$ ). We conclude that supplementation in dairy cows with homeopathic product showed no efficacy in reducing SCC.

Keywords: mastitis, dairy cattle, homeopathy. 
LEAL, L.P. e COSTA, C. Utilização da homeopatia para redução da contagem de células somaticas (CCS) em vacas Girolando. PUBVET, Londrina, V. 7, N. 14, Ed. 237, Art. 1562, Julho, 2013.

\section{INTRODUÇÃO}

A produção mundial de leite, em 2008, chegou a mais de 578 bilhões de litros, segundo a Organização das Nações Unidas para Agricultura e Alimentação. De acordo com esta organização, os Estados Unidos lideram o ranking de países produtores com mais de 86 bilhões de litros produzidos, seguindo-se a Índia com produção de 44 bilhões. O Brasil aparece como 0 sexto maior produtor, com mais de 27 bilhões de litros. Em 2011/12 chega a 32 bilhões de litros (ALVES et al., 2010).

No Brasil, a produção de leite, como os outros segmentos da atual sociedade, é atividade cada vez mais competitiva. Portanto, é importante quantificar e qualificar os fatores que podem influenciá-la, buscando ganhos efetivos na quantidade e na qualidade do leite produzido (COLDEBELLA et al., 2004).

Langoni et al., (2011) a mastite, como uma das principais afecções de bovinos destinados a produção leiteira, impacta negativamente a economia, considerando-se a sua alta prevalência nos rebanhos. As perdas econômicas se devem a vários fatores, tais como a diminuição da produção, custos com mão de obra, honorários profissionais, gastos com medicamentos, morte ou descarte precoce de animais e queda na qualidade do produto final, com diminuição no rendimento industrial.

Classicamente a doença define-se como inflamação da glândula mamária, originada por traumas físicos, agentes químicos ou mais comumente à invasão de microrganismos patogênicos no canal do teto, facilitada principalmente pelas más condições de manejo e higiene. Caracterizada por alterações físico-químicas e microbiológicas no leite e no tecido glandular mamário, podendo ocorrer destruição parcial ou total do tecido, dependendo do agente etiológico envolvido (GUIMARÃES et al., 2011).

A doença é descrita em quase todos os mamíferos domésticos, assim como em humanos, e tem distribuição geográfica mundial. Condições climáticas, variação sazonal, densidade e confinamentos das populações de 
LEAL, L.P. e COSTA, C. Utilização da homeopatia para redução da contagem de células somaticas (CCS) em vacas Girolando. PUBVET, Londrina, V. 7, N. 14, Ed. 237, Art. 1562, Julho, 2013.

animais de criação e práticas de agricultura podem afetar a incidência e a etiologia. Porém, é de grande frequência e importância econômica em bovinos leiteiros cuja principal função é produzir leite para produtos lácteos (KAHN et al., 2008).

Nos últimos anos, a homeopatia tem se difundido na medicina veterinária. Na Alemanha, por exemplo, cerca de $90 \%$ dos veterinários usam medicamentos homeopáticos. Em particular, o setor de pecuária tem manifestado um aumento no interesse pelo tratamento homeopático, em virtude da proibição do uso de substâncias farmacologicamente ativas em animais que produzem alimentos. Isso tem gerado uma lacuna cada vez maior no tratamento dos animais, ao que deve somar-se o desenvolvimento de resistência dos microorganismos em conseqüência do uso excessivo de antibióticos (MARTINS et al., 2007).

Segundo Arenales et al., (2002) o princípio básico da homeopatia é a utilização de medicamentos dinamizados, ou seja, produtos preparados a partir de substâncias animais, vegetais, minerais ou tecidos doentes. Na dinâmica desta preparação a matéria oriunda desta substância impregna as moléculas do álcool (ou açúcar) utilizado determinando nesta as impressões energéticas, sem alterar sua forma química. Com isso o objetivo deste trabalho foi avaliar a eficácia da homeopatia para redução da contagem de células somáticas (CCS) em vacas da raça Girolando.

\section{MASTITE BOVINA}

\subsection{IMPORTÂNCIA E CONCEITOS}

A mamite ou mastite, processo inflamatório da glândula mamária, é muito frequente e pode ser considerada como a mais importante das doenças que afetam os rebanhos leiteiros em todo o mundo. Tal afirmação encontra respaldo nos prejuízos econômicos provocados pela doença e pelas evidências de risco para a saúde pública, ocasionados pela possibilidade de veiculação por 
LEAL, L.P. e COSTA, C. Utilização da homeopatia para redução da contagem de células somaticas (CCS) em vacas Girolando. PUBVET, Londrina, V. 7, N. 14, Ed. 237, Art. 1562, Julho, 2013.

meio do leite, os agentes infecciosos causadores da doença, muitos deles patogênicos para o homem (MARQUES, 2006).

As perdas na produção de leite atribuídas às mastites subclínicas alcançam de $10 \%$ a $26 \%$ do total da produção, de acordo com grau de intensidade do processo inflamatório, da prevalência da doença, da patogenicidade do agente infeccioso e do estágio de lactação. Além da diminuição na produção, observa-se perda da qualidade do leite e da função do parênquima glandular, tornando o úbere uma reserva de patógenos (MARTINS et al. 2007).

Segundo Marques, (2006) os prejuízos econômicos, em termos de números ou cifras, sobre perdas ocasionadas por esta doença em rebanhos leiteiros, muitas informações circulam em publicações especializadas, quase todas obtidas a partir de dados de rebanhos americanos, cotados em dólar, cifras essas que assustam ao falar em algo como US\$200/vaca/ano. Outras consequências são a perda da qualidade do leite, uma vez fica alterada a composição físico-química com diminuição considerável das taxas de gordura, proteínas, açúcares e o aumento dos níveis de sais minerais, ocasionando o desequilíbrio salino e a perda da estabilidade térmica do leite.

Embora inúmeros sejam os agentes causadores do processo infeccioso, investigações sobre sua etiologia demonstraram que $90 \%$ ou mais dos casos têm como agentes etiológicos os estafilococos e os estreptococos. $\mathrm{Na}$ atualidade, Staphylococcus aureus é provavelmente o agente etiológico mais frequentemente isolado das mastites bovinas, e esta predominância ocorreu após o advento dos antibióticos e o seu uso indiscriminado, favorecendo o microorganismo adquirir resistência (MARTINS et al. 2007).

Dependendo do agente envolvido, a mamite tem duas formas de apresentação ou formas de transmissão. A mamite contagiosa é aquela causada por microorganismos bacterianos que são parasitas obrigatórios da glândula mamária, ou seja, vivem no ambiente interno e externo da glândula mamária. A contaminação ocorre mediante elemento de ligação de vaca para vaca, e/ou de um quarto doente e um quarto sadio. Isto é possível no 
LEAL, L.P. e COSTA, C. Utilização da homeopatia para redução da contagem de células somaticas (CCS) em vacas Girolando. PUBVET, Londrina, V. 7, N. 14, Ed. 237, Art. 1562, Julho, 2013.

momento da ordenha, pelas mãos do ordenhador, e de teteiras na ordenha mecânica. Os principais agentes são; Staphylococcus aureus, Staphylococcus coagulase negativo, Streptococcus agalactiae, Streptococcus uberis, Corynebacterium bovis (MARQUES, 2006).

A mamite ambiental é aquela causada por microorganismos que vivem no ambiente de ordenha ou de curral, principalmente no esterco, e até mesmo na água de bebida ou de limpeza. Os agentes ambientais são oportunistas, os principais são Escherichia coli, Klebsiella $s p$, Enterobacter $s p$, Pseudomonas aeroginosa, Streptococcus dysgalactiae. A transmissão os microorganismos pode ocorrer no período entre as ordenhas, principalmente, quando as vacas se deitam nos ambientes durante a ordenha, pelas mãos do ordenhador e/ou teteiras (MARQUES, 2006).

Estudos epidemiológicos prévios sobre fatores de risco identificaram características relacionadas ao animal, ao ambiente, aos procedimentos de manejo e ao equipamento de ordenha, associadas à mastite bovina e à variação da Contagem de células somáticas (CCS) (COENTRÃO et al., 2008).

De acordo com suas manifestações, a mastite pode ser classificada em forma clínica e subclínica (SANTOS; GRIEBLER, 2006). A primeira forma apresenta sinais evidentes, tais como, edema, aumento de temperatura, endurecimento, dor na glândula mamária, grumos e pus ou qualquer alteração das características do leite. O diagnóstico é realizado pelo uso da caneca de fundo preto ou telado onde se visualizam as alterações macroscópicas do leite (RIBEIRO et al., 2003).

A gravidade é classificada como, hiperaguda que se caracteriza como a inflamação grave com tumefação, calor e dor do quarto, havendo intensa reação sistêmica que pode ser fatal. A forma aguda se apresenta como inflamação grave sem reação sistêmica acentuada. Já a subaguda é uma inflamação moderada com anormalidade persistente no leite (KAHN et al., 2008).

No tratamento da mastite clínica na lactação se faz com administração de antimicrobianos pela via intramamária e pelas vias sistêmicas. A resposta 
LEAL, L.P. e COSTA, C. Utilização da homeopatia para redução da contagem de células somaticas (CCS) em vacas Girolando. PUBVET, Londrina, V. 7, N. 14, Ed. 237, Art. 1562, Julho, 2013.

ao tratamento varia muito, com taxas de recuperação entre 40-70\%. Esses resultados são devidos às diferenças na susceptibilidade de vários microrganismos diante das drogas, à duração da infecção antes do tratamento, à idade do animal, ao grau de lesão do tecido glandular e do tipo de resposta inflamatória da glândula mamária diante da agressão causada pelos diferentes patógenos (MARQUES, 2006).

A combinação de terapia sistêmica e intramamária é a prática mais efetiva, sendo que o numero de dias de tratamento de mamite clínica com os antimicrobianos sistêmicos e/ou intramamário não deve ultrapassar a cinco, uma vez que no intervalo de 3 a 5 dias ocorrem os maiores índices de cura clínica. Caso não obtém sucesso neste intervalo, deverão ser reavaliadas as amostras de leite submetidas a exames microbiológicos, e para realização de antibiogramas, para estabelecer a natureza dos microrganismos (MARQUES, 2006).

As drogas antiinflamatórias não-esteróides (DINE) são amplamente usadas no tratamento da mastite aguda como flunixina meglumina, flurbiprofeno, carprofeno e cetoprofeno foram estudados como tratamento em mastite por coliformes ou mastite induzida por toxinas experimental (KAHN et al., 2008).

De acordo com Ribeiro et al., (2003) na forma subclínica não se observam alterações macroscópicas e sim alterações na composição do leite; portanto, não apresenta sinais visíveis de inflamação do úbere. A contagem de células somáticas no leite é o indicador mais usado em programas de controle e prevenção da mastite subclínica em todo o mundo. O diagnostico pode ser detectado pela contagem direta (laboratório) ou indireta de células somáticas presente no leite. O California Mastitis Test (CMT) é um dos testes mais usuais para o diagnóstico da mastite subclínica, sendo um indicador indireto da contagem de células somáticas no leite.

Vários fatores podem influenciar a variação da CCS de vacas em lactação, como idade, ordem de parto, período de lactação, mês e estação do ano. Porém o estado de infecção é o principal fator responsável pela variação 
LEAL, L.P. e COSTA, C. Utilização da homeopatia para redução da contagem de células somaticas (CCS) em vacas Girolando. PUBVET, Londrina, V. 7, N. 14, Ed. 237, Art. 1562, Julho, 2013.

da CCS. Observaram que a CCS de vacas de limite 200.000 células $/ \mathrm{mL}$ foi o mais indicado para estimar uma nova infecção intramamária (SOUZA et al., 2009).

As células somáticas encontradas no leite pertencem a dois grupos, as células epiteliais secretoras de leite e os leucócitos (neutrófilos, macrófagos e linfócitos). O número e a proporção desses tipos de células são influenciados pelos estados fisiológicos e patológicos da glândula mamária. No leite de quartos mamários livres de infecção, predominam os macrófagos (35 a 79\%), seguidos por neutrófilos ( 3 a 26\%), linfócitos (10 a 24\%) e células epiteliais ( 2 a 15\%); no leite de quartos mamários infectados, os neutrófilos podem alcançar quase $100 \%$ do total de células (SOUZA et al., 2005).

Dentre os agentes etiológicos mais isolados em casos de mastite subclínica destacam-se os Staphylococcus coagulase positivos e coagulase negativos, os Streptococcus sps e o Corynebacterium bovis (RIBEIRO et al., 2003).

Tratamentos de mastites subclínicas com antibiótico, durante a lactação apresentam resultados variáveis quanto ao sucesso das terapias, assim como nos índices de recuperação, principalmente para aquelas causadas por estafilococos e estreptococos (ALMEIDA et al., 2005).

Trabalhos realizados por Marques, (2006) na fase inicial da lactação, em vacas infectadas por S. aureus, E. coli e Proteus spp, índices de recuperação entre $79 \%$ e $85 \%$, após tratamento com cloranfenicol e gentamicina. Outros tratamentos, entretanto, não apresentaram resultados satisfatórios, principalmente diante das infecções subclínicas causadas por $S$. aureus. Os custos com diagnósticos, medicamentos, descarte do leite e a taxa de cura bacteriológica muitas vezes inferior a 50\%, principalmente em infecções por $S$. aureus, fazem com que os tratamentos sejam considerados antieconômicos. 
LEAL, L.P. e COSTA, C. Utilização da homeopatia para redução da contagem de células somaticas (CCS) em vacas Girolando. PUBVET, Londrina, V. 7, N. 14, Ed. 237, Art. 1562, Julho, 2013.

\subsection{IMPORTÂNCIA DA CCS NOS PROGRAMAS DE QUALIDADE}

A contagem de células somáticas (CCS) é critério mundialmente utilizado por indústrias, produtores e entidades governamentais para o monitoramento da mastite em nível individual, de rebanhos e para avaliação da qualidade do leite. A CCS determina a quantidade de leucócitos e células epiteliais presentes no leite. Quando ocorre inflamação, há um aumento considerável nesta contagem (SILVA; NOGUEIRA, 2010).

Para melhorar a qualidade do leite e garantir um alimento seguro e de alto valor nutricional, e fundamental o controle da mastite nos rebanhos. Muitos esforços têm sido empregados para o seu controle. Tem-se adotado o estabelecimento de pagamento por qualidade, baseado na redução da contagem de células somáticas por mililitro de leite, que reflete o nível de ocorrência de mastite (LANGONI et al., 2011).

Segundo MAPA, 2011 a Instrução Normativa No 62, de 29 de dezembro de 2011; relata padrão de contagem de células somáticas aceitáveis no leite, destacando sua importância quando se pretende trabalhar com um programa de qualidade, ou seja, estar dentro de padrões estabelecidos para que tenha uma produção de leite com baixa CCS, consequentemente a um aumento no preço por litro de leite produzido.

\subsection{HOMEOPATIA VETERINÁRIA}

A homeopatia surgiu na Alemanha através do médico alemão Cristiano Frederico Samuel Hahnemann, publicando seu livro básico, Organon da Arte de curar em 1810. O nome homeopatia foi criado por Hahnemann utilizando palavras de origem grega, com o intuito de reforçar a Lei de semelhança que reage esta terapêutica ( Homeos - Semelhante / Pathos - moléstia). A homeopatia no Brasil, fundada por Dr. Benoit Mure - 1840 e Dr. João Vicente Martins. Ambos fundaram no Rio de janeiro, o Instituto Homeopático do Brasil, que passou a se chamar Instituto Hahnemanniano Brasileiro, onde em 1914 foi 
LEAL, L.P. e COSTA, C. Utilização da homeopatia para redução da contagem de células somaticas (CCS) em vacas Girolando. PUBVET, Londrina, V. 7, N. 14, Ed. 237, Art. 1562, Julho, 2013.

fundada a Faculdade Hahnemanniana, hoje Faculdade de Medicina e Cirurgia do Rio de janeiro (BENEZ et al., 2002).

Como toda ciência, na homeopatia existe algumas abordagens diferentes, onde ouve alternativas para sua descoberta e sua eficiência; sempre utilizando como base os quatro pilares fundamentais, que são: A experimentação no homem com saúde, quando o Hahnemann questionava os sintomas de um paciente com malária (1790) e resolveu fazer a autoexperimentação e anotar os sintomas e sensações que sentia; conclui-se que o mecanismo de cura da malária ocorria pelas semelhanças dos sintomas que causava nos pacientes. A lei de Semelhança, é o parâmetro de rotina na busca dos sintomas semelhantes, encontramos o medicamento mais indicado para cada paciente. O Medicamento único, Hahnemann defendia e recomendava a utilização de medicamento único, para um tratamento correto, o ideal é a medicação que engloba a sintomatologia do paciente. E o Medicamento dinamizado e diluído, o medicamento homeopático não é encontrado na sua forma natural da substância medicamentosa. Hahnemann preconiza que as substâncias sejam diluídas e dinamizadas (misturadas), para que estimulem de forma mais eficaz o restabelecimento da saúde dos pacientes (BENEZ et al., 2002).

Os bioterápicos ou nosódios (homeopáticos) são medicamentos preparados a partir de excreções, secreções, tecidos e órgãos de animais e vegetais, fisiológicos ou patológicos, ou ainda microrganismos, podendo ser aplicados com aspectos preventivos, uma vez que poderá ser utilizado o agente etiológico de uma determinada doença (ALMEIDA et al., 2005).

Segundo Silva et al. (2011) os compostos ou combinações homeopáticas, esporádica e erroneamente chamados de complexo homeopático, são a associação de homeopatias em uma única preparação. A origem do termo, neste contexto, advém da ocorrência de doenças chamadas complexas, nas quais duas doenças dissimilares instalam-se no mesmo indivíduo. Combinações homeopáticas foram capazes de induzir à redução na contagem de células 
somáticas de vacas leiteiras e de induzir cura de mastite clínica em vacas e búfalas.

É cada vez maior o uso de produtos homeopáticos por parte de pequenos produtores do sul do Brasil, que têm utilizado esses produtos alternativos por serem muito mais econômicos, diminuindo os custos de produção e remunerando melhor o produto final (SIGNORETTI et al., 2010).

As características dos medicamentos homeopáticos (diluição e dinamização) além de não intoxicarem o animal, não poluem o meio ambiente e nem deixam resíduos, permitindo uma produção de alimentos mais puros e saudáveis para a população, uma vez que sua utilização reduz a necessidade do uso de defensivos e medicamentos químicos (TELLES et al., 2008).

O modo de ação do medicamento homeopático no organismo dos indivíduos quando experimentados, induzem sintomas das patogenias. Quando utilizado na clínica, agem, fazendo o paciente desenvolver os mecanismos de cura. Mas necessita de mais aprofundamento das pesquisas para ter mais informações desta ação (BENEZ et al., 2002).

O uso de medicação homeopática no sal mineral ou na ração concentrada é uma alternativa por não serem onerosos, não são determinantes de contaminações ambientais, e dos indivíduos que manejam estes produtos, não causando problemas de saúde pública, em relação a produtos químicos; não causam prejuízos na indústria pela interferência nos processos de fabricação de produtos lácteos e, também, nos produtos da cadeia da carne bovina (SIGNORETTI et al., 2010).

\section{MATERIAL E MÉTODOS}

O experimento foi realizado na Fazenda São Paulo I, município de Iraí de Minas - MG, onde a principal atividade da fazenda é a produção leite. A rotina de ordenha segue com a lavagem dos tetos quando sujos de barro com água em seguida faz o teste da caneca de fundo preto para detecção de mastite clínica, seguindo com pré-dipping (base de iodo $0.5 \%$ ), após 30 segundos em 
LEAL, L.P. e COSTA, C. Utilização da homeopatia para redução da contagem de células somaticas (CCS) em vacas Girolando. PUBVET, Londrina, V. 7, N. 14, Ed. 237, Art. 1562, Julho, 2013.

média, secagem dos tetos com papel toalha descartável (um papel por teto) fazendo a ordenha em seguida; após a ordenha faz-se o pós-dipping (base de Iodo $1 \%$ ) com imersão de iodo em todo teto, em duas ordenhas diárias, as 5:00 e 15:00 horas, respectivamente.

Possui 60 vacas em lactação da raça Girolando, com grau de sangue de $3 / 4$ a $7 / 8$ holandesa, idade entre 2 e 5 anos, com produção média de 20 litros/animal/dia. Das 60 vacas foram selecionadas 48 , que iriam permanecer no experimento durante o período que foi de 100 dias, inicio 14 de fevereiro á 24 de maio de 2012.

Para o experimento as vacas em lactação $(n=48)$ foram divididas em dois lotes. Um com vacas abaixo de 120 dias de lactação (24 vacas) e outro com vacas acima de 120 dias de lactação (24 vacas), cada lote foi subdividido aleatoriamente em dois grupos de 12 vacas, sendo um grupo controle (T1) e um grupo tratamento (T2) com vacas abaixo de 120 dias de lactação.

Fazendo outro grupo controle (T3) e um grupo tratamento (T4) com vacas acima de 120 dias de lactação. Os grupos de tratamento foram o (T2) e (T4) que receberam 10 gramas de homeopático nos primeiros15 dias de tratamento e os demais 85 dias receberam 5 gramas, que foram fornecido uma vez ao dia durante a ordenha da tarde, juntamente com 500 gramas de ração que as vacas recebem individualmente no momento da ordenha. Os grupos controle (T1 e T3) não receberam homeopático, foram utilizados para métodos de comparação com os grupos tratados (T2 e T4).

As vacas que receberam produto homeopático foram separadas das outras com uma fina corda de algodão amarrada no pescoço para facilitar a separação, também brinco auricular para identificação. O produto homeopático comercial utilizado apresentou à seguinte formula: Carbo animalis $\mathrm{CH} 12$, Phytolacca decandra $\mathrm{CH}$ 12, Sulphur $\mathrm{CH}$ 12, lac vaccinum $\mathrm{CH}$ 12, Pulsatilla nigricans $\mathrm{CH}$ 30, Veículo 100 gramas.

Durante o experimento foram realizados quatro análises de CCS individualmente, com intervalo médio de trinta dias. As vacas que deram mastite clínica no período do experimento foram retiradas das analises, por 
motivo de estarem com alta resposta inflamatória, ou seja, alta quantidade de CCS.

A contagem de células somáticas foi realizada por método direto (análise eletrônica), realizada na clínica do leite ESALQ - USP (Escola Superior de Agricultura Luiz de Queiroz - Universidade de São Paulo). O leite para analise foi colhido em tubos apropriados com Bronopol (conservante), sendo feitas colheitas individuais durante a ordenha da tarde mediante ao registro do medidor de leite (presente na ordenha canalizada) e encaminhados para ponto de colheita do laboratório.

Os resultados das análises do leite foram analisados pelo programa bioestat 5.0 e expressos em médias. O teste utilizado foi o Kruskal-Wallis onde comparou o numero de CCS dos grupos avaliados. Os dados foram significativos quando $(P<0.05)$.

\section{RESULTADOS}

Ao analisar a Tabela 1, verificou-se que a CCS das vacas abaixo de 120 dias de lactação do grupo controle e do grupo de tratamento suplementadas com homeopatia no período de 100 dias, os resultados não se diferenciaram estatisticamente $(P>0.05)$.

TABELA 1. Analise média das Contagem Células Somáticas* individuais de vacas abaixo de 120 dias de lactação suplementadas e não suplementadas com produto homeopático.

\begin{tabular}{lccccc}
\hline \multicolumn{1}{c}{ Grupos } & n & D0 & D30 & D65 & D100 \\
\hline Controle (T1) & 12 & 325,83 & 170,63 & 284,75 & 395,41 \\
Tratamento (T2) & 12 & 429,58 & 293,58 & 330,09 & 403,63 \\
\hline
\end{tabular}

$(* \times 1000$ células $/ \mathrm{mL}) \mathrm{n}$ : numero de vacas

$(P>0.05) \quad D:$ Dia que realizou a análise 
Na Tabela 2 observou-se que a CCS das vacas acima de 120 dias de lactação do grupo controle e grupo tratamento suplementadas com homeopatia no período de 100 dias também não se diferenciaram estatisticamente $(P>0.05)$.

TABELA 2. Analise média das Contagem de Células Somáticas* individuais de vacas acima de 120 dias de lactação suplementadas ou não suplementadas com produto homeopático.

\begin{tabular}{lccccc}
\hline \multicolumn{1}{c}{ Grupos } & n & D0 & D30 & D65 & D100 \\
\hline Controle (T3) & 12 & 491,81 & 292,7 & 415,18 & 468,72 \\
Tratamento (T4) & 12 & 376,66 & 486,0 & 579,81 & 602,41 \\
\hline
\end{tabular}

$(* \times 1000$ células/ $\mathrm{mL}) \quad \mathrm{n}$ : numero de vacas

$(P>0.05) \quad D:$ Dia que realizou a análise

Ao avaliar os casos de mastite clínica durante o experimento, em ambos os grupos de tratamento ( $\mathrm{T} 2$ e T4) não houve um menor número de casos clínicos que os grupos controle (T1 e T3). TABELA 4.

TABELA 3. Numero de casos de mastite clínica no período experimental dos grupos controle e tratamento.

\begin{tabular}{cccccc}
\hline Grupos & D0 & D30 & D65 & D100 & Total \\
\hline T1 & 0 & 1 & 0 & 0 & 1 \\
T2 & 0 & 0 & 1 & 1 & 2 \\
T3 & 0 & 1 & 2 & 0 & 3 \\
T4 & 0 & 3 & 0 & 1 & 4 \\
\hline
\end{tabular}

D: Dias de experimento 
LEAL, L.P. e COSTA, C. Utilização da homeopatia para redução da contagem de células somaticas (CCS) em vacas Girolando. PUBVET, Londrina, V. 7, N. 14, Ed. 237, Art. 1562, Julho, 2013.

\section{DISCUSSÃO}

De acordo com os resultados apresentados na TABELA 2 e 3, não houve diferença significante $(P>0.05)$ na contagem de células somática dos grupos tratados com o produto homeopático. No entanto Silva et al., (2011), suplementaram 32 vacas holandesas com produto homeopático por 63 dias, houve uma tendência de aumento na CCS quando fornecida para vacas com boa saúde da glândula mamária.

Segundo Telles et al., (2008) em experimento realizado em Campo Grande estado do Mato Grosso do Sul utilizando-se vacas holandesas com mastite subclínica, com reação positiva de 3 cruzes e recebendo fornecimento de homeopático diario via ração, 100 gramas duas em vezes ao dia, durante 12 dias, verificou-se uma redução da CCS.

Resultado semelhante encontrado por Martins et al. (2007) realizado no Paraná, utilizando 32 animais com quadro infeccioso de mastite sublínica, detectado pelo teste de (CMT), com dosagem de homeopático de 300 gramas/dia por animal, durante 90 dias. Constataram-se que na evolução do experimento houve redução das porcentagens de $44,5 \%$ para 3,9\% de mastite subclínica, redução estatisticamente significativa $(P<0.05)$; demonstraram então possibilidade da utilização de medicamentos homeopáticos com resultados rápidos sem haver perda na produção leiteira, não causando prejuízo econômico ao produtor no decorrer do tratamento, pois as vacas continuaram sendo ordenhadas e o leite comercializado.

Os resultados de Santos; Griebeler (2006) realizado no Rio Grande do Sul avaliaram a eficiência e os custos para tratamento de mastite bovina utilizando produto homeopático. Em um grupo de 7 animais em 7 dias eles apresentaram melhora, quando utilizaram medicamentos convencional em 7 animais, um deles não apresentou melhora. O estudo sugere que tratamento homeopático da mastite apresenta eficiência semelhante, mas com custos inferiores $(10,9 \%)$. 
LEAL, L.P. e COSTA, C. Utilização da homeopatia para redução da contagem de células somaticas (CCS) em vacas Girolando. PUBVET, Londrina, V. 7, N. 14, Ed. 237, Art. 1562, Julho, 2013.

Neste trabalho não houve diferença estatística na CCS no período avaliado. Pode ser justificado pela dosagem do homeopático utilizada não seja suficiente para que o organismo do animal responda com seu mecanismo de cura. Portanto torna-se necessário que desenvolva outros experimentos por período maior, como em duas estações diferentes do ano (inverno e verão), com número de animais maiores, manejos diferenciados e dosagens diferentes para observar se os resultados são eficazes ou não.

Almeida et al. (2005) também avaliaram a eficiência da homeopatia em 50 quartos mamários para tratamento de mastite subclínica em bovinos. Onde o bioterápico na potência $12 \mathrm{CH}$ foi produzido a partir de amostras de leite dos quartos infectados e administrado três vezes ao dia, por via oral (dosagem de $0,5 \mathrm{~mL}$ ), durante 21 dias. As análises microbiológicas e CMT foram realizadas 7, 14 e 21 dias após o início do tratamento. Observou-se que a taxa de cura microbiológica foi maior $(p<0,01)$ no grupo tratado quando comparado ao grupo controle, bem como a cura específica para $S$. aureus e $S$. agalactiae $(p<0,05)$. Os resultados obtidos foram considerados satisfatórios, mas há necessidade de mais pesquisas, metodologias, trabalhos cientificamente comprovados para que os resultados sejam confiáveis e passíveis de repetição.

Em experimento realizado em Colina - SP, utilizando-se 8 vacas leiteiras mestiças em rebanho recebendo diariamente 5 gramas/animal/dia de produto homeopático comercial no concentrado para o controle de endoparasitas e ectoparasitas e mastite. No período de nove meses, correspondente a uma lactação, os resultados obtidos demonstraram que, com bom manejo nutricional e uso diário de produtos homeopáticos, é possível produzir leite de qualidade, em um sistema de produção leiteira. Ao usar o gado mestiço europeu $x$ zebu não houve necessidade de medicar com produtos alopáticos nenhuma vaca do rebanho, portanto o autor ressalta a necessidade de realizar experimentos semelhante para avaliar com um grupo controle, não submetido ao tratamento homeopático (SIGNORETTI et al., 2010).

Em casos de mastite devem ser levados em consideração alguns níveis, como: mastite clínica: igual ou inferior a 1\%; mastite subclínica: igual ou 
LEAL, L.P. e COSTA, C. Utilização da homeopatia para redução da contagem de células somaticas (CCS) em vacas Girolando. PUBVET, Londrina, V. 7, N. 14, Ed. 237, Art. 1562, Julho, 2013.

inferior a 15\%; vacas recém-paridas com mastite: menor que 10\%; contagem celular: abaixo de 250.000 células/ml (SILVA; NOGUEIRA, 2010).

Segundo Signoretti et al., (2010) cooperativas têm estimulado o uso de produtos homeopáticos por parte dos produtores de leite, inclusive remunerando melhor o leite produzido com bonificação de $1 \%$ no preço final do leite, devido melhor qualidade do leite produzido.

Conforme o padrão de qualidade do leite estabelecido pelo MAPA, até 2014 o numero de CCS aceitável é até 600.000 células $/ \mathrm{mL}$, portanto as médias de CCS dos grupos avaliados dos animais acima e abaixo de 120 dias de lactação estão de acordo com o IN 62, Tabela 2 e 3.

\section{CONCLUSÃO}

Conclui-se que a utilização da homeopatia não reduziu a contagem de células somáticas (CCS) em matrizes leiteiras da raça Girolando.

\section{REFERÊNCIAS}

ALMEIDA, A. C.; SOARES, T. M. P.; SILVA, D. B.; SILVEIRA, A. L.; FIORINI, J. E.; FONSECA, Y. M. Eficácia de tratamento homeopático no controle da mastite subclinica em bovinos. 2005.

Veterinária Notícias, Uberlândia, v. 11, n. 2, p. 53-59, 2005.

ALVES, A., MARINHO, C., ABREU, V., BARROS, K. M., Boletim setorial do agronegócio Bovinocultura leiteira. SEBRAE. 2010. Disponível em: <http://www.sebrae.com.br> Acessado em: 12 MAI 2012.

ARENALES, M. C. Homeopatia em gado de corte. I Conferência virtual global sobre produção orgânica de bovinos de corte, Embrapa. 2002.

BENEZ, B.; LATHOUD, C. J.; WOLFF, M. T.; Manual de homeopatia veterinária, Indicações clínicas e patológicas - Teoria e Prática. ROBE. São Paulo, 2002.

COENTRÃO, C. M.; SOUZA, G. N.; BRITO, J. R. F.; PAIVA E BRITO, M. A. V.; LILENBAUM, W. Fatores de risco para mastite subclínicas em vacas leiteiras. Arquivo Brasileiro de Medicina Veterinária e Zootecnia., v.60, n.2, p.283-288, 2008.

COLDEBELLA, A.; MACHADO, P. F.; DEMÉTRIO, C. G. B.; RIBEIRO JUNIOR, P. J.; MEYER, P. M.; CORASSIN, C. H.; CASSOLI, L. D.; Contagem de Células Somáticas e Produção de Leite em Vacas Holandesas Confinadas. Revista Brasileira de Zootecnia., v.33, n.3, p.623-634, 2004.

GUimARÃES, E. B.; FARIA, F. J. C.; GONÇALVES, J. L.; SILVA, L.; GOMES, M. F. F.; TERRA, V. J. B.; IV Mostra científica Famez, ANAIS. 2011. p.160-165. Disponível em: <http://www.mca.ufms.br>. Acessado em: 10 MAR 2012. 
KAHN, C. M.; LINE, S.; JURANDIR, J.; Manual Merck de Veterinária - $9^{\circ}$ Ed. São Paulo: Roca, p.957-964, 2008.

LANGONI, H.; PENACHIO, D. S.; CITADELLA, J. C. C.; LAUTINO F.; FACCIOLI MARTINS, P. Y.; LUCHEIS, S. B.; MENOZZI, B. D.; SILVA, A. V.; Aspectos microbiológicos e de qualidade de leite bovino. Pesquisa Veterinária Brasileira., p.1059-1065, 2011.

MARQUES, D. C.; Criação de Bovinos. $7^{\circ}$ Ed. rev. Atual. e ampl. Belo Horizonte - CVP Consultoria Veterinária e Publicações, p.435-450, 2006.

MARTINS, C. R.; VIERIA, E. C.; GAZIM, Z. C.; MASSAMBANI, C.; Tratamento de Mastite Subclínica por meio de Suplementação Mineral Homeopática da Dieta de Vacas Leiteiras em Lactação - Estudo de Caso. Cultura Homeopática • p. 16-19 • abr-mai-jun • no 19, 2007.

MAPA. Ministério da Agricultura, Pecuária e do Abastecimento. Instrução Normativa $\mathbf{n}^{\circ} \mathbf{6 2}$, de 29 de dezembro de 2011.

RIBERIO, M. E. R.; PETRINI, L. A.; AITA, M. F.; BALBINOTTI, M.; STUMPF JR, W.; GOMES, J. F.; SCHRAMM, R. C.; MARTINS, P. R.; BARBOSA, R. S.; Relação entre mastite clínica, subclínica infecciosa e não infecciosa em unidades de produção leiteiras na região sul do Rio Grande do sul. Revista brasileira de Agrociência, v.9, n.3, p.287-290, jul-set, 2003.

SANTOS, J. S.; GRIEBELER, S. A.; Tratamento Homeopático da Mastite do Gado leiteiro. Cultura Homeopática, p. 9-11, jan-fev-mar. № 14, 2006.

SIGNORETTI, R. D.; VERÍSSIMO, C. J.; SOUZA, F. H. M.; OLIVEIRA, E. M.; DIB, V.; Aspectos produtivos e sanitários de vacas mestiças leiteiras tratadas com produtos homeopáticos. 2010. Arquivo do Instituto Biológico, São Paulo, v.77, n.4, p.625-633, out./dez, 2010.

SILVA, J. R. M.; BITENCOUR, L. L.; OLIVEIRA, B. M. L.; DIAS JUNIOR, G. S.; LOPES, F.; CAPORALE, G. M. M.; SCHEFFER, K. C.; PEREIRA, R. A. N.; PEREIRA, M. N.; Suplementação de vacas leiteiras com homeopatia: células somáticas do leite, cortisol e imunidade. 2011.

Arquivo Brasileiro de Medicina Veterinária e Zootecnia. vol.63 n.4 Belo Horizonte ago, 2011.

SILVA, M. V. M.; NOGUEIRA, J.L.; Mastite: Controle e profilaxia no rebanho bovino. Revista Científica Eletrônica de Medicina Veterinária - ISSN: 1679-7353, Ano VIII - No 15, 2010.

SOUZA, G. N.; SILVA, M. R.; SOBRINHOL, F. S.; COELHO, R. O.; BRITO, M. A. V. P.; BRITO, J. R. F.; Efeito da temperatura e do tempo de armazenamento sobre a contagem de células somáticas no leite. Arquivo Brasileiro de Medicina Veterinária e Zootecnia., v.57, n.5, p.830-834, 2005.

SOUZA, G. N.; BRITO, J. R. F.; MOREIRA, E. C.; BRITO, M. A. V. P.; SILVA, M. V. G. B.; Variação da contagem de células somáticas em vacas leiteiras de acordo com patógenos da mastite. Arquivo Brasileiro de Medicina Veterinária e Zootecnia., v.61, n.5, p.10151020, 2009.

TELLES, D.Z.; SILVESTRE, L.; GOMES, O.P. Avaliação microbiológica de amostras de leite oriundo de mamites sub-clínicas antes e após tratamento homeopático. Congresso Brasileiro De Medicina Veterinária, 35., 2008. Anais. Gramado: Sociedade Brasileira de Medicina Veterinária, Disponível em: <http://www.sovergs.com.br>. Acessado em: 7 NOV 2011. 